\title{
Fatigue in primary biliary cirrhosis
}

This patient developed severe fatigue as a result of primary biliary cirrhosis in her $40 \mathrm{~s}$. She describes her frustration with the reluctance of successive clinicians to recognise the severity of her fatigue and the damage it was doing

\author{
Matilda Hale patient ${ }^{1}$, Julia L Newton professor of ageing and medicine ${ }^{2}$, David $\mathrm{E} J \mathrm{~J}$ Jones professor \\ of liver immunology ${ }^{2}$
}

${ }^{1}$ Cramlington, Northumberland, UK; ${ }^{2}$ Newcastle University and Newcastle Hospitals NHS Foundation Trust, Freeman Hospital, Newcastle upon Tyne NE7 7DN, UK

This is one of a series of occasional articles by patients about their experiences that offer lessons to doctors. The BMJ welcomes contributions to the series. Please contact Peter Lapsley (plapsley@bmj.com) for guidance.

I was diagnosed with the liver disease primary biliary cirrhosis (PBC) in January 1986, at 42 years old. Unusually, my general practitioner recognised it and immediately referred me to the Freeman Hospital in Newcastle. Many people take years to get a diagnosis, as doctors often do not recognise the symptoms or attribute them to other illnesses such as depression. At the hospital I was told that there was no treatment for my disease but that they would look after me. I was told that it affected about nine women for every one man, and there were more known cases in northeast England than anywhere else in the world. However, I knew no one else with this disease, I had never heard of it nor had any of my friends, and so it was a very lonely time.

By the time I was diagnosed, I knew I was different from my friends. I was always more tired than they were; less able to cope with a day out; ached all over, especially in my legs and arms; and could not lift heavy pans easily. I was used to being an active person: I played squash and badminton, did a lot of walking and gardening, did my own decorating, and had a good social life. As a single parent with two teenage children, this was a difficult time for me. I did not tell my children about my illness and tried to hide it from them. I used to take them to school then go home and sleep for several hours each day, setting the alarm for $2 \mathrm{pm}$ so that I could pull myself together, iron a shirt and blouse for the next day for their school uniforms, and think about what I could make for an evening meal (most days it was a take-away or something very simple).

As the years passed, I became more and more fatigued. I was always tired, but I could not sleep properly at night. My daughter went to university, and I am embarrassed to say it was a relief because I then only had my son at home for most of the year. Eventually, he also left home, and that made my life easier because they did not see how I was coping, and on my bad days (which by then outnumbered my good ones) I could stay in bed until lunchtime if necessary. Some days I managed to get up, shower, get dressed, and do something. Those were good days. Normal days were those when I got up eventually, had a shower by lunchtime, and then just sat and read or watched television for the rest of the day. On bad days I usually stayed in bed, although I would tend to get up around $4 \mathrm{pm}$ and sit in my dressing gown until it was time to go back to bed. My social life deteriorated to the point where I rarely went out in the evenings, and during the day I did not like to plan ahead as I was never sure how much I would be able to manage. When friends visited I used to make a supreme effort to act normally and would put on a good show while they stayed with me, but when they left I would be so exhausted I would be tearful and I would take several days to recover.

\section{"That can't be a problem: your blood tests are fine"}

During this time I often mentioned the fatigue to the hospital doctors, who varied greatly in their attitude to it. Some were very sympathetic, although they couldn't really offer any treatment. Others obviously felt I should pull myself together. One suggested I try to take up squash again. Almost universally there was a sense that, as my liver function tests were quite good, this could not really be a problem related to my liver disease. Eventually, David Jones became my consultant. He always believed in the fatigue, and, although there was still no treatment, just knowing that he took on board what I was saying was a great help and made me feel better. 
In 1994 a group of liver patients set up a support group, LIVErNORTH, based at the Freeman Hospital. I was a founder member and joined the committee as honorary secretary. This brought me into contact with many other people with PBC and helped me, as it meant I no longer felt alone. Talking to others, it was apparent that most of us had the same problem with fatigue, and we also realised that we had problems with memory. We compared notes on how we coped-in reality we did not cope very well-and on our shared experiences with doctors who just didn't understand or accept fatigue as a problem. I felt I had "dumbed down" and no longer expected so much of myself. There were times when I would be in the middle of some housework and would just have to walk away and take to my bed, abandoning the ironing, vacuuming, or whatever. The ironing board would stand unused for days, the vacuum cleaner would remain in the middle of the room, and I would walk round it but would not have the energy to put it away. Because my brain was still working reasonably well, I knew I was not coping. At meetings we talked about how we no longer achieved what we thought we should - we certainly could not keep up with our "normal" friends. I walked with a group but eventually stopped as I was told, very nicely, that I was slowing them down too much: to be honest, it was a relief to be able to stop as it had become a nightmare for me.

The problem with fatigue is that it is hidden. I don't look different from other people: when I say I am tired they tell me how tired they are, and if I try to explain the difference they do not understand what I am talking about. When I was first diagnosed my GP told me that I would never get any sympathy as I would always look reasonably well and my symptoms would have no impact on other people's understanding of my life. The fatigue that I and my fellow PBC patients contend with is mind numbing. You feel as if you are in a fog, you can hardly lift one foot in front of the other, everything is so difficult. You go shopping and then cannot unpack the groceries, so the frozen food defrosts and has to be thrown out. You plan a meal and forget to turn on the oven; if you do turn on the oven and cook the meat, you cannot manage to do the vegetables so it ends up being sandwiches.

In 1999 I had a liver transplant as my liver had deteriorated to such a point that I was not able to function, and a transplant was the only option. While I am better than before my operation, I continue to feel tired, although it is not the same as the previous fatigue. Recently, PBC patients were asked if we would be prepared to consider participating in a trial of a drug that might improve our fatigue, but which could have side effects. My answer was immediate: I would consider any treatment that might improve my fatigue. When I discussed it with other PBC patients, they all had the same attitude. Everyone said they would consider any treatment that might offer a way out of this existence. We feel we are in a no man's land-on the outside looking in, or sometimes locked inside and cannot get out. We do not feel part of the normal population, and this is very sad. We would love to be the lively, energetic people we once were, and if there is anything that can make us feel that way, we will take it like a shot.

Competing interests: All authors declare; no support from any organisation for the submitted work, no financial relationships with any organisations that might have an interest in the submitted work in the previous three years, no other relationships or activities that could appear to have influenced the submitted work

Provenance and peer review: Not commissioned; not externally peer reviewed.

Patient consent: None required; the patient is the corresponding author.

Accepted: 04 July 2012

Cite this as: BMJ 2012;345:e7004

(c) BMJ Publishing Group Ltd 2012 


\section{The clinicians' perspective}

Fatigue is a common and debilitating symptom in chronic inflammatory disease that can affect all age groups and can impact enormously on quality of life. One of the problems frequently faced by patients who experience fatigue is a sense of disbelief by friends, family, and even healthcare professionals as to the nature and origins of the symptom that affects them so dramatically. This sense of lack of belief in those around them can contribute to the social isolation exemplified by Tilly's description, and which patients are always prone to because of their lack of physical capability. In the UK, our group based in Newcastle has worked with the patient support group LIVErNorth for over a decade, and we have begun to change the perception of fatigue in one particular chronic disease, the autoimmune liver disease primary biliary cirrhosis (PBC). However, we continue to be surprised by the lack of appreciation of those both inside and outside our field as to the enormity of the implication that fatigue has for individuals who experience it.

PBC is a cholestatic autoimmune liver disease in which fatigue is experienced by at least half of patients. In about $25 \%$ of patients the fatigue is severe enough to have a serious impact on the life quality of patients through loss of capacity to work, to undertake hobbies, and to lead a normal social life. Critically, fatigue is not associated with severity of underlying liver disease, nor does it seem to respond to therapy with ursodeoxycholic acid, an agent that slows progression of the disease. The lack of association with disease severity can lead all too often to a scenario where the doctor perceives PBC to be well controlled because of improved liver biochemistry, whereas the patient finds this apparently well controlled disease is still giving them life altering fatigue.

Equally critically, in PBC there is no evidence to suggest that fatigue is a result of depression or associated comorbidity, neither of which are seen at increased frequency in the disease. Despite this, there is a tendency for clinicians to make assumptions about the presence of depression simply because a patient is fatigued. This assumption can further challenge the patient-physician relationship and can lead to a pattern of clinical "buck passing" as the various clinicians involved in the management of these often complex cases argue that the fatigue is "not my problem" (although, of course, it always remains the patient's problem).

As our work on mechanisms of fatigue in PBC leads towards specific therapies (our group has shown cardiac, skeletal muscle, and a range of other biological associates of fatigue in PBC and is about to commence trials of therapy, delivered in an always supportive environment that seeks to help patients to understand their problem and to cope with its impacts) there is a new hope for fatigued PBC patients. The history of fatigue in PBC, the impact the symptom has on patients, and the approach taken by a frequently sceptical (but ultimately wrong) medical profession which in many cases increased rather than reduced that impact holds important lessons for other chronic inflammatory diseases where patients are still experiencing the issues outlined by Tilly.

Julia Newton, David Jones

\section{Useful resources for patients and health professionals}

- LIVErNORTH (www.livernorth org uk/index.htm)—A support group for adult patients with liver disease based at the Freeman Hospital in Newcastle upon Tyne. Run entirely by volunteers, all its services are provided free to liver patients and their carers and families in northern England

- Although it is a regional charity, LIVErNORTH has members throughout the UK. It has also helped produce a DVD, A Patient's Guide to PBC (Primary Biliary Cirrhosis), which is available in both European and North American formats and has been sent to people throughout Europe and North America (http://www.ennovations.co.uk/primary-biliary-cirrhosis-dvd)

- PBCers Organisation (http://pbcers.org/)—A US based patient support group

- Canadian PBC Society (www.pbc-society.ca)—Can be contacted via info@pbc-society.ca 